\title{
Knowledge and Skills of Medical Students about Stroke Patients: A Review
}

Samad Shams Vahdati ${ }^{1}$, Payman Moharamzadeh², Zahra Parsian ${ }^{2}$,Sahar Bagheri ${ }^{2}$, Roshan Fahimi $^{2}$

1. Road Traffic Injury Research Center and Emergency Medicine Research Team, Tabriz University of Medical Science, Tabriz, Iran

2. Emergency Medicine Research Team, Tabriz University of Medical Science, Tabriz, Iran

\begin{abstract}
Stroke, a leading cause of neurological disability in the world, is the third major reason for mortality after cancer and heart diseases. It is an epidemic emerging worldwide, especially in the low and middle-income countries. Most of the patients survived from stroke are not treated completely and have a life with disability and complications. Therefore, it is necessary that medical students be trained and educate in a standardized manner through focused lectures, interactive workshops, and bedside teaching sessions so that they can deal with these patients and manage potentially disabling neurological emergencies such as stroke correctly.
\end{abstract}

Keywords: Stroke; Prescription; Medical student 


\section{Introduction}

Stroke, a leading cause of neurological disability in the world, is the third major reason for mortality following cancer and cardiac diseases. It is an emerging epidemic worldwide, especially in the low and middle-income countries. Most of the patients who survive the stroke are not treated completely and continue a life with disability. It is necessary for caregivers to involve inpatient care and educational intervention studies focussing on stroke survivors. Medical students are often challenged finding out and discussing the complexities associated with the diagnosis of stroke. Accordingly, learning to effectively manage and handle patients with stroke needs didactic methods and proper training (1-4). Considering huge burden of stroke on care providers, the level of knowledge about stroke and its initial diagnosis and management, both in the general population and physicians, should proportionately match its prevalence. Stroke is an emergency condition; i.e. it is of immense importance not to waste the golden time (5).

Surveys from all around the world have revealed that the generic knowledge about stroke in the general population is, unfortunately, inadequate $(6,7)$. Information literacy was defined by Zurkowski for the first time in 1974; it refers to the ability to have access to the required information from a mass information (8). As an independent learner, one should know how to recognize and have easy and fast access to the required information and know the way to evaluate and utilize the information when needed. The collection of these abilities for independent learning is named information literacy (9). One having information literacy will be able to:

1. Define quantity and scope and type of required information

2. Have effective access to needed information

\section{Critic information and references}

4. Combine selected information with previous knowledge

5. Utilize information effectively for specific purposes such as writing and presenting an article

6. Be aware of social economic and legal access and use of information from legal and ethical aspects (10).

Training students with mental abilities and critical thought and ability to learn independently after graduation for whole life is for sure the aim of any higher education. Information literacy is the key to lifelong learning. Information literacy increases the student's ability to evaluate, manage and use information and information technology helps the students to learn without a time and place limitations. For evaluating information literacy of people, standards should be defined (11). Medical students are symbols of future physicians. In recent years' studies about fatigue and occupational burnout of physicians, high level of job burnout and psychological problems during the last year of education have been shown $(12,13)$. This can interfere with learning and appropriate management of the students in vital and critical situations. Critical situations such as acute myocardial infarction and cerebrovascular accidents both require precise information and clear image of one's knowledge. As both diseases have high mortality and morbidity rate without timely diagnose and treatment, specific attention is required.

Khaja and et al., in 2005 in their study, evaluated the pre-interns' ability to prescribe. In this study, 539 students of which $66.2 \%$ were female were evaluated. $96.1 \%$ of the data related to the physicians including name, signature and recipe, date and patients' 
identifying data were written completely (14). In $50.2 \%$ of cases, drug form, dose or consumption instruction were written completely, implying that the students were not trained well enough to prescribe before the internship. The most common problem was drug form. In 2016, Sudha et al. studied prescribing skills of medical students. Students 4-8 terms prior to graduation were asked to write a prescription for a clinical scenario. 281 out of 350 students that were invited participated in the study. 169 agreed that they hadn't prescribed correctly. 134 named lack of training before graduation as the cause of their inadequate skill. 90\% claimed that educational classes during 3rd and 4th year of internship can affect their learning. This study showed that there is a wide gap for writing a prescription among medical students. Most of the students believed that patient's management was not discussed well. In this study, there was a lack of familiarity with the generic names and types of medications (14, 15). Ignacio et al., in 2015, evaluated the confidence of drug prescription amongst young physicians. 200 questionnaires were sent to health care centres. $73.5 \%$ of the physicians answered the questions completely. $68 \%$ of interns responded a high confidence. More than $80 \%$ of contributors were sure about their antibiotic prescription. This study showed that despite medical graduation certainty about the prescribed medication, there is a need for recurrent evaluation of their performance (16). In 2016, Dyasanoor and et al., in their study, evaluated attitude toward drug prescription. In this study, 5 prescriptions of Oxford students in India were evaluated. The results of this study showed that $2 \%$ paid attention to patients' information and 31\% considered physician's information and $67 \%$ considered drug information. This study showed that more efforts are needed for improving the quality of prescriptions (17). In 1386, Moatar et al. evaluated the general skills of last year medical students from their own point of view. In this descriptive analytic survey, 71 medical students who were under training in Shiraz University of Medical Sciences evaluated themselves by 101 item questionnaires according to Likert scale in 17 general medicine competency. The graduates of medicine of this university had a ranking higher than $3 / 5$. This study showed that the insistence of Shiraz University of Medical Sciences education program on patients is higher than the society. Thus, improving community required medical skills such as geriatric medicine, nutrition, care management, advanced procedures and continuing education programs can culminate in the improvement of care in the society (18). In 2011, Magbouli et al. evaluated medical student's knowledge about narcotic analgesics to suggest probable solutions by recognizing the obstacles. This was a descriptive study in which 200-last year medical students of Tabriz University of Medical Sciences participated. 86.5\% answered the questions completely. $59 \%$ of students who answered completely had pessimistic attitude compared with $41 \%$ who had optimistic attitude. $73.74 \%$ evaluated their knowledge and ability to administrate narcotics inadequately. $49.16 \%$ admitted that they have low knowledge about the side effects of narcotics and appropriate management of their side effects. $77.6 \%$ were keen to attend educational classes or workshops for pain management if they were held. The findings of this study showed the anxiety of last year medical students owing to the lack of pain management knowledge (19).

Sole medical education is not sufficient in the promotion of skills of the medicine students. Supplementary educational workshops in medical education systems with emphasis on the importance of these educational elements can be beneficial $(20,21)$.

Therefore, it is necessary that medical students and health care workers, in particular, 
are trained and educated in a standardized manner through focused lectures, interactive workshops, and bedside teaching sessions. This will enable them to deal with and correctly manage the prevalent and potentially disabling neurological emergencies, such as stroke, or paraplegia, etc. It is also important to target neurological topics to better prepare and help the medical students to assist their future and current patients, respectively. Public education needs to raise awareness of prevention, initial symptoms, and emergency measures of medical students for correctly managing patients with stroke symptoms and signs at the right time.
Ultimately, we recommend that the government should intensify its budget on health issues and specially to create stroke rehabilitation units in all states and hospitals. It is important that all aspects of stroke management, both in general and particular, be targeted to make sure that all medical students are well-trained with at least the basic steps to take while facing a case of stroke. On a wider scale, it is recommended for public education campaigns to be conducted to increase the general awareness of the population about the prevention, signs, symptoms, and emergency steps to be taken when facing a case of stroke.

\section{References}

1. Sacco RL, Boden-Albala B, Gan R, Chen X, Kargman DE, Shea S, Paik MC, Hauser WA. Stroke incidence among white, black, and hispanic residents of an urban community the Northern Manhattan Stroke Study. American journal of epidemiology. 1998 Feb 1;147(3):259-68.

2. Sacco RL, Boden-Albala B, Abel G, Lin IF, Elkind M, Hauser WA, Paik MC, Shea S. Race-ethnic disparities in the impact of stroke risk factors. Stroke. 2001 Aug 1;32(8):1725-31.

3. Aho K, Harmsen P, Hatano S, Marquardsen J, Smirnov VE, Strasser T. Cerebrovascular disease in the community: results of a WHO collaborative study. Bulletin of the World Health Organization. 1980;58(1):113.

4. World Health Organization. Fact sheet: the top ten causes of death. Fact sheet. 2008 Oct(310).. https://www.who.int/mediacentre/factsheets/fs310.pdf. Updated May. 2016

5. Khubaib MU, Rathore FA, Waqas A, Jan MM, Sohail S. Knowledge Regarding Basic Facts of Stroke Among Final Year MBBS Students and House Officers: A Cross-Sectional Survey of 708 Respondents from Pakistan. Cureus. 2016 Mar;8(3).

6. Spark JI, Blest N, Sandison S, Puckridge PJ, Saleem HA, Russell DA. Stroke and transient ischaemic attack awareness. Med J Aust. 2011 Jul 4;195(1):16-9.

7. Johnston SC, Fayad PB, Gorelick PB, Hanley DF, Shwayder PM, Van Husen D, Weiskopf T. Prevalence and knowledge of transient ischemic attack among US adults. Neurology. 2003 May 13;60(9):1429-34.

8. Zurkowski, Paul G. "The Information Service Environment Relationships and Priorities. Related Paper No. 5." (1974).

9. Parirokh M, Abassi Z. Information literacy education: methods and strategies. proceeding of user education and information literacy in libraries and information centers. 2004; 21-22. Mashhad, Iran: Organization of libraries, Museums and document center of Astan Guds Razavi. 2004:197-214.

10. Zamani E. Information literacy standards. Inf Sci Technol. 2003;19:34-41.

11. Bass EB, Fortin AH, Morrison G, Wills S, Mumford LM, Goroll AH. National survey of clerkship directors in internal medicine on the competencies that should be addressed in the medicine core clerkship. The American journal of medicine. 1997 Jun 30;102(6):564-71.

12. Noorbala A, Fakhraie SA. Surveying the frequency of psychiatric symptoms among senior medical and nonmedical’x vùwCE/,fl students of Tehran University. Iranian Journal of Psychiatry and Clinical Psychology. 2002;7(3):27.

13. Akkasheh G, Sepehrmanesh Z, Ahmadvand AF. Prevalence of burnout in senior medical students of Kashan University of Medical Sciences in 2008. Qom university of medical sciences Journal. 2010;4(3); 37-41

14. Al Khaja KA, Handu SS, James H, Mathur VS, Sequeira RP. Assessing prescription writing skills of pre-clerkship medical students in a problem-based learning curriculum. Int J Clin Pharmacol Ther. 2005 Sep 1;43(9):429-35. 
15. Sudha MJ, Viveka S, Remya S. Assessment of prescription writing skills among undergraduate medical students. International Journal of Basic \& Clinical Pharmacology. 2016;5(4):1586-93.

16. Ignacio $D$, Sealy $P$, Clement $Y$. Confidence in Prescription Writing among Junior Physicians in Trinidad and Tobago. The West Indian medical journal. 2015 Sep;64(4):407.

17. Akdere H, Oztekin I, Arda E, Aktoz T, Turan FN, Burgazli KM. Analgesic Effects of Oligonol, Acupuncture and Quantum Light Therapy on Chronic Nonbacterial Prostatitis. Iranian Red Crescent Medical Journal. 2015 Apr;17(4); e26006.

18. Moattari M, Fallahzadeh M. Senior medical students' self evaluation of their capability in general competencies in Shiraz University of Medical Sciences. Iranian Journal of Medical Education. 2008 Mar 15;7(2):371-7.

19. Jhaleh Naderi N, Maghbouli M. Attitude of senior medical students on the use of opioid to manage patients' pain. Iranian Journal of Medical Education. 2011 Oct 15;11(3):299-300.

20. Amiri H, Gholipour C, Mokhtarpour M, Vahdati SS, Aghdam YH, Bakhshayeshi M. Two-day primary trauma care workshop: early and late evaluation of knowledge and practice. European Journal of Emergency Medicine. 2013 Apr $1 ; 20(2): 130-2$.

21. Amiri H, Vahdati SS. Two-Day Primary Trauma Care Workshop-is it Beneficial?. Turkish Journal of Emergency Medicine. 2009;9(1):008-11. 